\title{
Uma análise discursiva sobre os sentidos da promoção da saúde incorporados à Estratégia Saúde da Família ${ }^{*}$
}

\author{
Mônica Soares da Fonseca Beato ${ }^{1}$ \\ Cornelis Johannes Van Stralen ${ }^{2}$ \\ Izabel Christina Friche Passos ${ }^{3}$
}

BEATO, M.S.F.; STRALEN, C.J.; PASSOS, I.C.F. A discursive analysis of health promotion meanings incorporated into the Family Health Strategy. Interface - Comunic., Saude, Educ., v.15, n.37, p.529-37, abr./jun. 2011.

The purpose of this study is to discuss meanings about the set of ideas concerning health promotion in the context of the Family Health Strategy. A case study was carried out in Belo Horizonte and the guidelines related to health promotion in the primary care services of this municipality are brought to discussion. Then the discursive practices and intervention strategies of a Family Health team are analyzed. We approach the frequent fragmentation and polarization between the clinic and the programmatic collective actions, both based on logics that are rarely in touch with each other, forming a single strategy by the force of institutional norms. However, the formulation of a mental health promotion project by the Family Health team expresses other meanings, much closer to a critical conception of the health promotion ideas.

Keywords: Health promotion.

Empowerment. Family Health Strategy. Discursive practices.
O objetivo deste estudo de caso é analisar significações sobre o ideário da promoção da saúde presentes no contexto da Estratégia Saúde da Família. O estudo de caso foi realizado em Belo Horizonte e, por isso, inicialmente, são discutidas as diretrizes relacionadas à promoção da saúde na atenção básica deste município. Em seguida, são analisadas as práticas discursivas e as estratégias de intervenção de uma equipe de Saúde da Família. Evidenciamos a fragmentação e a polarização frequentes entre a clínica e as ações coletivas programáticas, ambas pautadas em lógicas que raramente dialogam entre si, sobrepondo-se em uma só estratégia por força de normas institucionais. Entretanto, a construção de um projeto de promoção da saúde mental pela equipe de Saúde da Família remete a sentidos sobre promoção da saúde que estão mais próximos de uma concepção crítica do ideário.

Palavras-chave: Promoção da saúde. Empowerment. Estratégia Saúde da Família. Práticas discursivas.

\footnotetext{
*Elaborado com base em Beato (2006), pesquisa aprovada pelo Comitê de Ética em Pesquisa da Secretaria Municipal de Saúde de Belo Horizonte e realizada conforme as diretrizes éticas recomendadas pela Resolução 196/96 e pela

1 Laboratório de GNUPO Instituições e Redes Sociais, Faculdade de Filosofia e Ciências Humanas, Universidade Federal de Minas Gerais (FAFICH/UFMG).

Avenida Antônio Carlos, 4000, FAFICH, sala 4040. Belo Horizonte MG. 31.270-901. msoaresbeato@gmail.com 2,3 Programa de PósGraduação em Psicologia, Faculdade de Filosofia

e Ciências Humanas, Universidade Federal de Minas Gerais.
} 


\section{Introdução}

O ideário da saúde pública que é denominado promoção da saúde tem sido apontado, na literatura científica, como uma proposição inovadora, mas polissêmica, capaz de gerar deslizamentos semânticos em situações concretas de intervenção (Carvalho, Gastaldo, 2008; Traverso-Yépez, 2007; Carvalho, 2004; Castiel, 2004). Tomando esse enunciado como pressuposto, analisamos a promoção da saúde como um objeto social disputado (Foucault, 2004), que pode tomar diferentes contornos quando se transforma em estratégia nos dispositivos. O conceito de dispositivo também é referência em nossa análise, assim como Foucault (1993) o entende, isto é, como uma invenção social que instaura saberes, produz "verdades", como uma rede que se pode estabelecer a partir de múltiplos discursos, produzindo subjetividades.

Interessa-nos discutir os sentidos que a promoção da saúde incorpora no contexto específico da Estratégia Saúde da Família do Sistema Único de Saúde - SUS. Inicialmente, são analisados documentos internacionais e nacionais, bem como as diretrizes específicas em Belo Horizonte. Em um segundo momento, a análise aborda o plano das ações cotidianas da atenção básica, o que nos aproxima das práticas discursivas e das estratégias de uma equipe de Saúde da Família. É preciso esclarecer que a pesquisa não teve como finalidade avaliar serviços de saúde ou as bases estruturais da atenção básica de Belo Horizonte. Apresenta, sim, uma discussão sobre as formas de significação da política de saúde na relação cotidiana entre gestores, profissionais e usuários.

\section{Os sentidos da promoção da saúde na atenção básica}

A base conceitual da promoção da saúde tem sido incorporada aos programas de Ministérios da Saúde de muitos países e aos projetos desenvolvidos pelo Terceiro Setor. Frequentemente, a expressão é encontrada em publicações científicas na área da saúde, inclusive em Psicologia. Em alguns casos, ela é empregada com a intenção de assegurar um discurso politicamente correto, enquanto em outros textos remete ao seu sentido estrito apregoado, atualmente, pela Organização Mundial da Saúde - OMS. Esta concepção se vincula a princípios como: integralidade, intersetorialidade, equidade, sustentabilidade, formação de redes sociais, participação social e empowerment (OMS, 1998).

Indistinções são comuns entre os termos educação em saúde, prevenção de doenças e promoção da saúde. Para a OMS (1998), o último deles tem uma atuação mais abrangente e pode, inclusive, envolver ações preventivas e educativas. De fato, a OMS orienta que as ações de promoção da saúde sejam desenvolvidas em cinco áreas-chave: construir e implementar políticas públicas saudáveis; criar ambientes favoráveis à saúde; desenvolver habilidades pessoais; fortalecer a ação comunitária; e reorientar os serviços de saúde.

O Programa Saúde Família (PSF), atualmente denominado Estratégia Saúde da Família, foi implantado a partir de 1994 para ser uma estratégia fortemente alicerçada na promoção da saúde, com sua lógica de territorialização e intersetorialidade, além do enfoque por problemas identificados em um dado coletivo (Mendes, 1996). Entre outras atribuições, cada equipe deve: conhecer a realidade do território, promover ações conjuntas com equipamentos governamentais e comunitários, discutir o conceito de cidadania enfatizando os direitos de saúde, e incentivar a participação da comunidade nas comissões locais e no conselho municipal. Dessa forma, espera-se que a equipe consiga trabalhar com a lógica da demanda, e não da simples oferta de um leque de ações programáticas, fazendo isso por meio do vínculo e da responsabilização pelos usuários (Brasil, 2006).

Sabe-se que as bases da Seguridade Social inscritas na Constituição e decorrentes do Movimento da Reforma Sanitária convivem com um pensamento privatista que torna a área social um terreno conflituoso e exposto às restrições de ajuste financeiro impostas pela Reforma do Estado (Franco, Merhy, 2003; Noronha, Soares, 2001). Desse modo, são priorizados pacotes de saúde pública que contemplam minimamente a população considerada de maior risco.

De forma entrelaçada ao campo discursivo normativo-institucional da política, a promoção da saúde é um paradigma polissêmico capaz de gerar deslizamentos semânticos e ideológicos nos 
microprocessos de produção de sentido cotidianos. Ao se materializar em projetos locais, tem sido constantemente atravessada por discursos variados - científicos, políticos, religiosos ou leigos -, os quais dão margem a diferentes e contraditórias possibilidades de ações. Cabe destacar que são, sobretudo, as polissemias em relação aos conceitos de risco, autonomia e comunidade que tornam esse paradigma amplo e útil para diferentes intencionalidades (Castiel, 2004). Os projetos podem se sustentar em uma forma sutil de vigilância e regulação do social por meio da biopolítica (Castel, 1987; Foucault, 1987, 1980), que acaba por operar através da liberdade de escolha.

Ortega (2003) argumenta que o problema das práticas baseadas no cálculo do risco seria a possibilidade de serem apolíticas e individualistas, com procedimentos que constroem bioidentidades. Ao invés de representar práticas discursivas de grupos específicos contemporâneos, esse problema origina-se do fato de a modernidade decompor o espaço público e voltar-se para o privatismo e o intimismo. Se a saúde tornou-se um bem supremo nos dois últimos séculos, o que indica a politização da vida ou o biopoder (Foucault, 1987 citado por Ortega, 2003), pode haver, paradoxalmente, um movimento antipolítico baseado no indivíduo desequilibrado e no esvaziamento da vida pública. Assim, a ideologia da intimidade transforma categorias políticas em unicamente psicológicas. $E$, por meio de numerosas práticas bioascéticas, o indivíduo demonstra, ou não, sua competência para cuidar de si e construir sua identidade. Desse modo, o indivíduo se constitui como autônomo e responsável por seus males, podendo ainda ser auxiliado por agentes/experts nomeados para orientá-lo.

Um conceito muito usado atualmente, não só na saúde pública, mas também nas políticas sociais como um todo e no Terceiro Setor, ratifica a polissemia de sentidos em questão. Empowerment referese ao agenciamento de indivíduos e de comunidades para assumirem maior autonomia e controle sobre os fatores que afetam a qualidade de vida. Carvalho (2004) sugere questionar qual é a teoria sobre o poder que sustenta esse conceito, bem como quais são as características das relações de poder concretas. As críticas a esse pressuposto têm ensejado elaborações no campo da saúde coletiva sobre um empowerment social/comunitário (Carvalho, Gastaldo, 2008), que é o eixo central da chamada 'nova promoção da saúde'.

\section{O referencial de análise}

Como já se pretendeu argumentar, promoção da saúde é um ideário assumido, no presente estudo, como um objeto social disputado que pode assumir diferentes formas quando se transforma em estratégia de ação, não se falando, por isso, em uma essência do objeto (Foucault, 2004). Seguindo a proposta desse autor, o trabalho em questão consiste em analisar as regras do discurso que tornam possível a ocorrência de certos enunciados, em determinado tempo e localização institucional. Essas regras configuram objetos e são referência para posições de sujeito em práticas discursivas. Por práticas discursivas podem-se nomear os recortes feitos pelos próprios pesquisadores, que veem alguma regularidade em um número de enunciados que estão submetidos às mesmas condições de existência. Todo enunciado possui regras históricas, legitimadas por condições institucionais e relações de poder. Utilizamos, na pesquisa, a Análise do Discurso francesa, não como uma técnica, mas como um instrumental teórico-metodológico que pode nos auxiliar na interpretação do corpus, devido à relação que é tecida entre linguagem e sociedade.

Desse modo, não se adota uma concepção essencialista de sujeito, entendendo-se a subjetividade como uma produção influenciada por formações discursivas diversas, que rompem com toda invariante universal. Uma visão naturalizada e moralizante de sujeito - aliás, próxima à que a ciência psicológica tradicional propunha - diferencia-se da visão sobre sujeitos e famílias imersos em redes sociais e, portanto, não nucleares. Desse modo, nas análises, são evitadas as polarizações, privilegiando-se pensar, de forma complexa, o campo em questão. 


\section{Construindo a pesquisa de campo}

Por se tratar de um estudo sobre significações em uma prática institucionalizada de cuidado, as diretrizes da instituição na qual os profissionais estão inseridos interferem muito no seu posicionamento. O cuidado em contextualizar as ações dos sujeitos de pesquisa nos levou a investigar, por meio de análise documental e entrevista semiestruturada com o gestor da atenção básica, a base conceitual e política que estruturava esse nível de atenção à saúde do SUS em Belo Horizonte, na época da pesquisa de campo.

Posteriormente, entre as mais de quinhentas equipes da Estratégia Saúde da Família existentes na capital mineira, pedimos que algumas fossem indicadas pela coordenação da atenção básica. As equipes deveriam ter estratégias de promoção da saúde bem-sucedidas para os padrões da gestão. Dos quatro centros de saúde sugeridos, o primeiro contatado por nós prontamente concordou em participar do estudo. Uma das três equipes dessa Unidade, responsável por pouco mais de 4.000 pessoas em um bairro periférico de Belo Horizonte, foi focalizada por nós, por indicação da gerente.

Após aproximação com o centro de saúde e consentimento dos trabalhadores da equipe, durante três meses, a primeira autora frequentou atividades e registrou, no diário de campo, observações sobre reuniões, intervenções com usuários (grupos, ações de educação em saúde, acolhimento) e reuniões da Comissão Local de Saúde. Além disso, as entrevistas semiestruturadas feitas com cada profissional da equipe e com a gerente da unidade foram gravadas e transcritas literalmente. A análise da implicação da pesquisadora no campo também foi útil. Triangulamos a análise documental, os dados observacionais registrados no diário de campo e as entrevistas transcritas. Como eixos de sistematização e tematização, evidenciaram-se: descrições sobre o contexto e sobre as atividades; interação da equipe com os usuários e com a pesquisadora; e significações sobre as atividades denominadas, pela equipe, como promoção da saúde. Na análise discursiva das entrevistas, a atenção foi direcionada para: interdiscursos, mudanças discursivas e reformulações, atos ilocucionários, destinatário(s), persuasão, captação e subversão da autoridade atribuída ao texto-fonte, polissemia, metáforas, vozes ativa e passiva, condições de produção daquele enunciado, esquecimento e jogos de verdade que dizem respeito a ganhos e interesses daqueles que estão na situação de entrevista (Charaudeau, Maingueneau, 2004).

\section{A estratégia em Belo Horizonte}

A atenção básica de Belo Horizonte é reconhecida, nacionalmente, por ser um sistema de característica assistencial, isto é, bastante vinculado à clínica. Em 2006, quando a pesquisa de campo foi realizada, havia 508 equipes de PSF trabalhando em 137 centros de saúde, as quais atendiam a uma população cadastrada de, aproximadamente, $78 \%$ do volume populacional correspondente, na época, a 1,7 milhão de moradores, em 412 mil famílias.

É relevante retomar alguns marcos históricos dessa estrutura. No início da década de 1990, a Secretaria Municipal de Saúde recebia grande influência da vertente teórica da saúde coletiva "vigilância da saúde" (Paim, 2003; Mendes, 1996), fortemente ancorada no ideário da promoção da saúde, no planejamento epidemiológico e nas ações coletivas programáticas. Pouco depois, pressupostos de sanitaristas identificados com o movimento "em defesa da vida", como a clínica ampliada, o trabalho vivo em ato e o acolhimento (Campos, 2005; Merhy, 2002), tornaram-se norteadores da atenção básica. Com a implantação municipal do PSF em 2002 e as exigências do Ministério, a vigilância da saúde volta a ter destaque na distribuição das equipes e na definição de ações prioritárias. Atualmente, coordenadores, gerentes das unidades básicas e, ainda, cada equipe têm a tarefa de planejar essa articulação entre os dois modelos, pensando-os como complementares.

O que a gente espera que a equipe faça é que ela dê conta da síntese dessas duas questões, até porque, se você trabalha só com a visão do planejamento e da epidemiologia, você não dá entrada para problemas muito importantes que não são captáveis ou são dificilmente captáveis pela via da epidemiologia. Nega uma parte grande do que faz as pessoas sofrerem. Então a gente avalia que é possível essa síntese. [gestor da atenção básica] 
Embora certa polarização entre as duas perspectivas se revele nas diretrizes (Belo Horizonte, 2003), um movimento de síntese é observado em documento posterior. No projeto "Promoção de modos de vida saudáveis" (Grupo de Promoção à Saúde..., 2006), a Secretaria Municipal propõe, aos serviços de atenção básica, a prática diária de abordagem individual dos casos de doenças crônicas e o fortalecimento da rede local para possível integração dessas pessoas em grupos de apoio, os quais não devem ser organizados de acordo com as doenças, mas com as questões psicossociais vivenciadas. Esse documento foi publicado após a realização do nosso estudo de caso com uma equipe da ESF e, por isso, não pudemos discuti-lo com a equipe. A coordenação nos informou, posteriormente, que o trabalho desse centro de saúde e de alguns outros subsidiou a construção do projeto.

Longe de entendermos essas duas vertentes em saúde coletiva como discordantes, compreendemos que são estruturadas em diferentes bases epistemológicas. Nossa intenção, no presente estudo, é analisar como esses e outros referenciais discursivos são articulados pelos profissionais com o ideário da promoção da saúde. É importante lembrar que tais profissionais também incorporam ao trabalho construções simbólicas e experiências de vida variadas.

\section{A equipe focalizada e sua rede de sentidos sobre promoção da saúde}

Uma característica da equipe investigada chamou nossa atenção desde o início. Era o processo de escuta e acolhimento que ocorria cotidianamente entre os próprios trabalhadores. Com exceção da mudança de três dos cinco Agentes Comunitários de Saúde, esse mesmo grupo de profissionais havia se constituído há dois anos e reunia-se regularmente, uma tarde por semana, para discutir o processo de trabalho. Em especial, eram colocados em questão os chamados grupos de promoção da saúde, cuja responsabilidade pela coordenação era dividida entre os integrantes da equipe. A satisfação do médico, da enfermeira e da auxiliar de enfermagem, por serem trabalhadores da atenção básica, somada à estabilidade temporal da composição da equipe, obviamente contribuiu para o aperfeiçoamento do processo de trabalho.

Ao monitorar o fluxo do acolhimento, eles perceberam que muitos usuários retornavam, com frequência, à unidade, até quatro vezes ao mês. Mantinham queixas mesmo depois de se consultarem com o médico, fazerem exames e consultas especializadas, sendo que alguns não tinham nem recebido diagnóstico de fundo orgânico. Não se contentando com a aplicação do rótulo de "poliqueixosos", tão comum entre conversas de profissionais da saúde, a equipe criou um projeto para qualificar essas demandas e intervir sobre elas. Entre as metas previstas no projeto elaborado pela própria equipe, denominado de projeto de saúde mental, estavam: criar grupos de suporte social e aumentar a satisfação, autonomia e humor social do usuário. Além dos grupos de artesanato, de obesidade, de coral e de convivência, o projeto envolvia sessões de terapia comunitária, abertas a interessados em geral e coordenadas pela equipe. Os trabalhos de Barreto (2004) e Boff (1999) eram os principais norteadores da equipe na coordenação das ações. Com base nesta estratégia, o usuário, inicialmente, passava por um processo chamado de escuta qualificada no consultório, com a enfermeira, podendo, então, ser convidado a participar de algum grupo.

Em todos os grupos, o apoio mútuo entre os usuários era cuidadosamente estabelecido com a troca de contatos telefônicos e datas de aniversário, e com a realização frequente de confraternizações, bailes e passeios. A concepção de grupo parecia se traduzir não só no fortalecimento do vínculo, por meio da afetividade e da identidade daquele coletivo, mas, também, em um espaço de ampliação do respeito à diferença. A equipe esperava facilitar um processo em que o usuário passasse a se sentir bem consigo mesmo a partir da confiança e da pertença, algo que os próprios profissionais também exercitavam nas reuniões da equipe. Entretanto, ainda que esses grupos se distanciassem da prescrição de hábitos de vida saudáveis, seu movimento às vezes recaía em outra fragmentação, pelo viés da psicologização dos problemas. Isto é, uma noção essencialista de interioridade psíquica era supervalorizada nos discursos. Em alguns enunciados, evidenciou-se a significativa aposta no sujeito como sendo capaz de mudar os rumos da vida, desconsiderando toda a complexidade dos problemas psicossociais. De todo modo, a equipe estava satisfeita pelos interessantes efeitos que esse dispositivo causava a muitos usuários no momento em que redefiniam suas queixas. 
É interessante mencionar algumas dificuldades comentadas por esses trabalhadores. Realizadas com procedimentos diferentes da estratégia anterior, as chamadas ações programáticas coletivas, com as mães de crianças desnutridas ou com asma, com os usuários hipertensos e os diabéticos, não tinham as mesmas repercussões positivas. A equipe acreditava que o problema, nestes casos, era a ausência de demanda por escuta e que a verticalidade das ações programáticas para as doenças prevalentes engessava a potencialidade criadora local. Em nossa análise, a própria condição da equipe como um grupo sujeito (Guattari, 1987) era descaracterizada nesses casos, problema que se reproduzia na relação com os usuários. O apelo ao sujeito que toma as rédeas do próprio destino, a partir do apoio de um grupo, mostrava-se um dispositivo insuficiente nesses casos. Foi curioso notar, nas entrevistas individuais, que, quando a pesquisadora perguntava sobre promoção da saúde, os profissionais remetiam ao projeto de saúde mental. Apenas quando se questionava diretamente se as ações programáticas também eram atividades de promoção da saúde, eles respondiam afirmativamente.

Em todos os casos, é possível afirmar ainda que os sentidos sobre promoção da saúde se diferenciavam entre os processos de compreender e intervir. Explicitar que saúde se relaciona, também, com fatores socioculturais fazia parte do repertório discursivo dos profissionais na interação com a pesquisadora. Contudo, as intervenções não acompanhavam a mesma configuração. Concordamos com Camargo Jr. (2005) ao afirmar que a racionalidade que condiciona a leitura das demandas, definindo as respostas que a atenção básica à saúde deve dar, separa respostas sociais e respostas terapêuticas.

Essa diferença, relacionada à setorialização das políticas sociais, fez-se tênue durante um levantamento sobre o território, desenvolvido pela equipe num curso de capacitação organizado pela Prefeitura de Belo Horizonte. A partir do conceito de representações sociais, da Psicologia Social, os profissionais se propuseram a investigar os modos de nascer, de viver e de morrer daquela comunidade. A área de abrangência dessa equipe é formada, de um lado, por ruas planas, calçadas e com saneamento básico - o risco médio -, e, de outro, por ruas curvas e estreitas, barracos sem reboco e com saneamento precário, aglomerados em pequenos espaços - o risco elevado. Desde a formulação do projeto, eles optaram por diferenciar a amostra em dois grupos: cinquenta entrevistados da área de risco elevado e o mesmo número da área de risco médio. Um ACS comentou os resultados da pesquisa, ao contrastar os dois grupos:

\begin{abstract}
Essa queda brusca no poder aquisitivo teve um retorno depressivo [nos entrevistados de risco médio]. O risco elevado, realmente, é o sofrimento do dia a dia, é uma população mais pobre, é uma população que vive com a criminalidade. A criminalidade é muito maior. Então tem a questão do tráfico. Tem o toque de recolher, então é um padrão de vida... não é um padrão de vida. A vida delas é um sofrimento. A depressão delas é porque elas sofrem. As pessoas [do risco elevado] convivem com a criminalidade e se sentem mais seguras do que as pessoas que moram aqui em cima [risco médio, onde o entrevistado mora]. Porque lá eles se sentem seguros, não pela polícia, mas justamente pela própria criminalidade que protege eles. Se você trata bem, não é acagüete nem nada, cê ta bem. Aqui não. Nós somos as vítimas. O risco médio é a vítima lá de baixo. [...] Juntando as pesquisas, você consegue realmente definir como é a cara da população. [ACS, em entrevista]
\end{abstract}

A afirmação do ACS é rica em muitos aspectos para uma análise aprofundada. Interessa-nos, neste artigo, apenas ponderar como o movimento da equipe tem potencialidade para ressignificar dispositivos que legitimam certas relações de poder, naturalizam ideologias e constroem identidades. Nada disso ocorre apenas em um nível que podemos chamar de intrapsíquico, estando na interlocução entre senso comum, ciência, imaginário social, regras instituídas e pertencimento a grupos específicos.

\title{
Considerações finais
}

Como conclusão geral da pesquisa, consideramos que, no campo discursivo analisado - tanto no plano da gestão quanto no da equipe de saúde -, faziam-se presentes sentidos sobre promoção da saúde abertos à ressignificação, em permanente construção. 
Parece-nos contraditório apregoar, como princípio fundamental da promoção da saúde, a ampliação da autonomia dos usuários sobre os determinantes da saúde, como fazem as diretrizes nacionais, mantendo dispositivos fragmentados no território e verticalmente engessados. Desse modo, a potencialização dos efeitos de atividades isoladas das equipes de atenção básica é limitada, mesmo que elas adotem um processo de trabalho tão interessante quanto se mostrou o da equipe escolhida para este estudo.

A respeito da forma como as diretrizes são absorvidas pela equipe da Estratégia Saúde da Família, suscita-nos ainda questionar se é possível, nesse contexto, escapar da produção de corpos e "mentes" que se autoprotejam de riscos. Tomando emprestadas duas expressões de Baptista (2001), acreditamos que o grande desafio da promoção da saúde na atenção básica é "descoisificar a diferença", escapando da "fabricação de indivíduos". A própria equipe pesquisada nos mostrou que estava abrindo caminhos possíveis, ao fortalecer redes sociais de apoio, ao abrir-se a uma escuta ampliada do sujeito para além da doença e ao tentar diluir o pensamento disciplinar e prescritivo.

\section{Colaboradores}

Mônica Soares da Fonseca Beato elaborou todas as etapas do artigo. Cornelis Johannes van Stralen e Izabel Christina Friche Passos participaram, igualmente, da discussão e da revisão do texto.

\section{Referências}

BAPTISTA, L.A. A cidade dos sábios: reflexões sobre a dinâmica social nas grandes cidades. São Paulo: Summus Editorial, 1999.

BARRETO, A. Terapia comunitária passo a passo. Fortaleza: LCR, 2004.

BEATO, M.S.F. Os sentidos da promoção da saúde na atenção básica: estudos de caso na Estratégia Saúde da Família em Belo Horizonte. 2006. Dissertação (Mestrado) Programa de Pós-graduação em Psicologia, Universidade Federal de Minas Gerais, Belo Horizonte. 2006.

BELO HORIZONTE. Secretaria Municipal de Saúde. BH-Vida: saúde integral. Diretrizes para o avanço e articulação do processo assistencial na SMSA para o período 20032004. Belo Horizonte: Secretaria Municipal de Saúde, 2003. (Mimeogr.).

BOFF, L. Saber cuidar. Petrópolis: Vozes, 1999.

BRASIL. Ministério da Saúde. Portaria 648, de 28/03/2006. Aprova a Política Nacional de Atenção Básica e Anexo (Política Nacional de Atenção Básica). Brasília: Ministério da Saúde, 2006.

CAMARGO JR., K.R. Das necessidades de saúde à demanda socialmente constituída. In: PINHEIRO, R.; MATTOS, R. (Orgs.). Construção social da demanda. Rio de Janeiro: UERJ/Cepesc/Abrasco, 2005. p.91-101.

CAMPOS, G.W.S. Saúde Paidéia. 2.ed. São Paulo: Hucitec, 2005.

CARVALHO, S.R. Os múltiplos sentidos da categoria "empowerment" no projeto de promoção à saúde. Cad. Saude Publica, n.20, v.4, p.1088-95, 2004. Disponível em: <http://www.scielo.br/pdf/csp/v20n4/24.pdf>. Acesso em: 13 dez. 10.

CARVALHO, S.R.; GASTALDO, D. Promoção à saúde e empoderamento: uma reflexão a partir das perspectivas crítico-social pós-estruturalista. Cienc. Saude Colet., v.13, supl.2, p.2009-40, 2008. Disponível em: <http://www.scielo.br/pdf/csc/v13s2/v13s2a07.pdf> Acesso em: $13 \mathrm{dez} .10$. 
CASTEL, R. A gestão dos riscos: da anti-psiquiatria à pós-psicanálise. Rio de Janeiro: Francisco Alves, 1987.

CASTIEL, L.D. Promoção de saúde e a sensibilidade epistemológica da categoria 'comunidade'. Rev. Saude Publica, v.38, n.5, p.615-22, 2004. Disponível em: <http://www.scielo.br/pdf/rsp/v38n5/21747.pdf>. Acesso em: 13 dez. 10.

CHARAUDEAU, P.; MAINGUENEAU, D. Dicionário de análise do discurso. São Paulo: Contexto, 2004.

FOUCAULT, M. A arqueologia do saber. Rio de Janeiro: Forense Universitária, 2004.

. Microfísica do poder. Rio de Janeiro: Graal, 1993.

O nascimento da clínica. Rio de Janeiro: Forense, 1987.

. História da sexualidade: a vontade de saber. Rio de Janeiro: Graal, 1980.

FRANCO, T.B.; MERHY, E.E. PSF: contradições de um programa destinado a mudanças do modelo assistencial. In: MERHY, E.E. et al. (Orgs.). O trabalho em saúde: olhando e experienciando o SUS no cotidiano. São Paulo: Hucitec, 2003. p.55-124.

GRUPO DE PROMOÇÃO À SAÚDE DA SECRETARIA MUNICIPAL DE SAÚDE DE BELO HORIZONTE. BH-SAÚDE, Projeto Promoção de Modos de Vida Saudáveis. Pensar BH Politica Social, n.16, p.21-4, 2006.

GUATTARI, F. Revolução molecular: pulsações políticas do desejo. São Paulo: Brasiliense, 1987.

MENDES, E.V. Uma agenda para a saúde. São Paulo: Hucitec, 1996.

MERHY, E.E. Saúde: a cartografia do trabalho vivo. São Paulo: Hucitec, 2002.

NORONHA, J.C.; SOARES, L.T. A política de saúde no Brasil nos anos 90. Cienc. Saude Colet., v.6, n.2, p. 445-50, 2001. Disponível em: <http://www.scielo.br/pdf/csc/ v6n2/7014.pdf >. Acesso em: $13 \mathrm{dez} .10$.

ORGANIZAÇÃO MUNDIAL DA SAÚDE - OMS. Promoción de la salud: glosario. Genebra: OMS, 1998. Disponível em: <http://whqlibdoc.who.int/hq/1998/WHO_HPR_ HEP 98.1 spa.pdf >. Acesso em: 22 mar. 2011.

ORTEGA, F. Práticas de ascese corporal e constituição de bioidentidades. Cad. Saude Coletiva, v. 11, n.1, p.59-77, 2003. Disponível em: <http://www.nesc.ufrj.br/ cadernos/2003_1/2003_1\%20FOrtega.pdf>. Acesso em: 13 dez. 10.

PAIM, J. Vigilância da saúde: tendências de reorientação de modelos assistenciais para a promoção da saúde. In: CZERESNIA, D. (Org.). Promoção à saúde: conceitos, reflexões, tendência. Rio de Janeiro: Fiocruz, 2003. p.161-71.

TRAVERSO-YÉPEZ, M. Dilemas na promoção da saúde no Brasil: reflexões em torno da política nacional. Interface - Comunic., Saude, Educ., v.11, n.22, p.223-8, 2007. Disponível em: <http://www.scielo.br/pdf/icse/v11n22/04.pdf>. Acesso em: 13 dez. 10. 
BEATO, M.S.F.; STRALEN, C.J.; PASSOS, I.C.F.

BEATO, M.S.F.; STRALEN, C.J.; PASSOS, I.C.F. Un análisis discursivo a respecto de los sentidos de la promoción de la salud integrados en la Estrategia Salud de la Familia. Interface - Comunic., Saude, Educ., v.15, n.37, p.529-37, abr./jun. 2011.

El objetivo de este estudio es investigar las concepciones del ideario de promoción de la salud en el ámbito de la Estrategia Salud de la Familia. El estudio de caso se llevó a cabo en Belo Horizonte, estado de Minas Gerais, Brasil, por lo que inicialmente se discuten algunas directrices de la atención primaria en este municipio. A continuación son analizadas las prácticas discursivas y las estrategias de intervención de un equipo de Salud de la Familia. Lo que más se evidencia es la fragmentación y la polarización frecuentes entre la clínica y las acciones colectivas proyectadas. Las dos son basadas en lógicas que raramente dialogan entre sí. Sin embargo, la construcción de un proyecto de promoción de la salud mental por parte del equipo revela otros sentidos a respecto de la promoción de la salud que se asemejan más a una concepción crítica del ideario.

Palabras clave: Promoción de la salud. Empowerment. Estrategia Salud de la Familia.

Recebido em 29/03/2010. Aprovado em 12/11/2010 
